\title{
Prediction of Deformation Properties of Steel SheEts BY NuMERICAl Simulation
}

\author{
Wessely, E.; Evin, E. \& TOMAS, M.
}

Abstract: Paper presents study results of localised deformation, described by FLC, at different deformation schemes. FLC are used for fracture prediction at crash and formability tests in automotive industry. In experiments were used two types of steel sheets: hot deep galvanized steel sheet DX54D and austenitic stainless steel DIN 1.4301. Limit localised deformations were researched by experimental tests using $C C D$ video camera recording and numerical simulation. Deformation schemes were modelled on tensile test specimens by different notch radii $(R 5, R 10, R 17.5, R 25)$. Reached forming limit curves from experiment and simulation were compared. There was shown good agreement of FLC experimentally measured and computed by numerical simulation.

Key words: local limit deformation, stress-strain state, forming limit diagram, CCD camera, FEM simulation
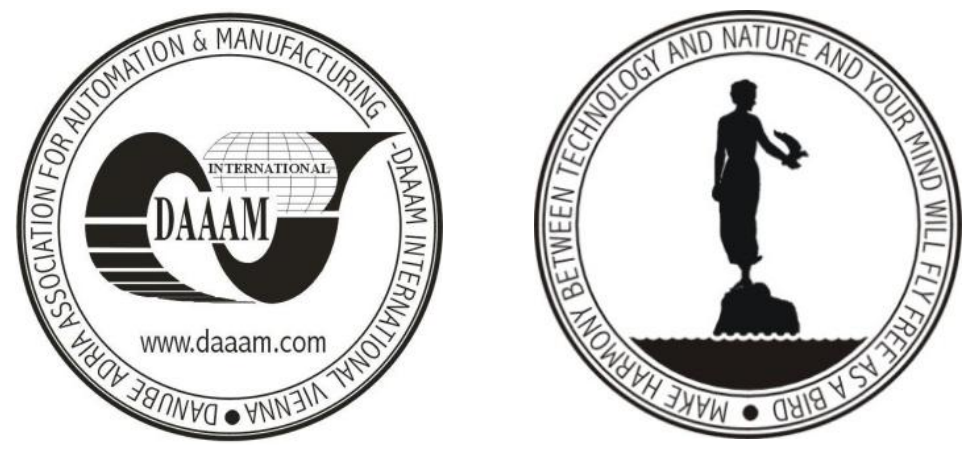

Authors' data: doc. Ing. Wessely, E[mil]*; Prof. Ing. Evin, E[mil]**; Ing. Tomas, M[iroslav]**, *University of Security Management in Kosice, Kukučínova 17, 040 01, Kosice, Slovakia, ** Technical University of Košice, Letna 9, 040 01, Kosice, Slovakia,wessely@vsbc.sk,Emil.Evin@tuke.sk, Miroslav.Tomas@tuke.sk

This Publication has to be referred as: Wessely, E[mil]; Evin, E[mil] \& Tomas, M[iroslav] (2012). Prediction of Deformation Properties of Steel Sheets by Numerical Simulation, Chapter 02 in DAAAM International Scientific Book 2012, pp. 019-026, B. Katalinic (Ed.), Published by DAAAM International, ISBN 978-3901509-86-5, ISSN 1726-9687, Vienna, Austria

DOI: $10.2507 /$ daaam.scibook.2012.02 
Wessely, E.; Evin, E. \& Tomas, M.: Prediction of Deformation Properties of Steel...

\section{Introduction}

Regarding economic and ecological requests the main appeal for design, material science and production technology engineers is car's body parts weight decreasing. Car's body components design strategies are fixed to optimisation of material selection from aspects of both weight minimisation at first and preservation or improvement of functional properties (safety, power, fuel consumption, comfort, etc.) (Hrivňák, 2004), (Čada, 2001), (Rosenberg, 2011). ULSAB studies point out weight reduction potential from steel sheets components resides in thinner steel sheets application with both higher strength properties and combined laser welded tailored blanks from these steel sheets (Tab. 1).

\begin{tabular}{|l|c|c|}
\hline & $\begin{array}{c}\text { Weight } \\
{[\mathrm{kg}]}\end{array}$ & $\begin{array}{c}\text { Torsional } \\
\text { stiffness } \\
{[\% / \mathrm{Nm}]}\end{array}$ \\
\hline Car's body based on typical high strength steels & 300 & $>15000$ \\
\hline ULSAB & 210 & $>19000$ \\
\hline Car's body skeleton based on austenitic steel sheets & 160 & $>25000$ \\
\hline
\end{tabular}

Tab. 1 Comparison of car's body parameters produced form different steel sheets

When applying the thinner steel sheets with higher strength properties it is necessary to presuppose the deterioration of formability technological characteristics. Formability, or reached deformation degree (the limit value) in sheet plane, respectively the necking of a cup wall thickness depends on material properties, stress-strain state, initial blank thickness and strain rate - Fig. 1 (Hrivňák, 2004), (Čada, 2001), (Ramaekers, 2000).

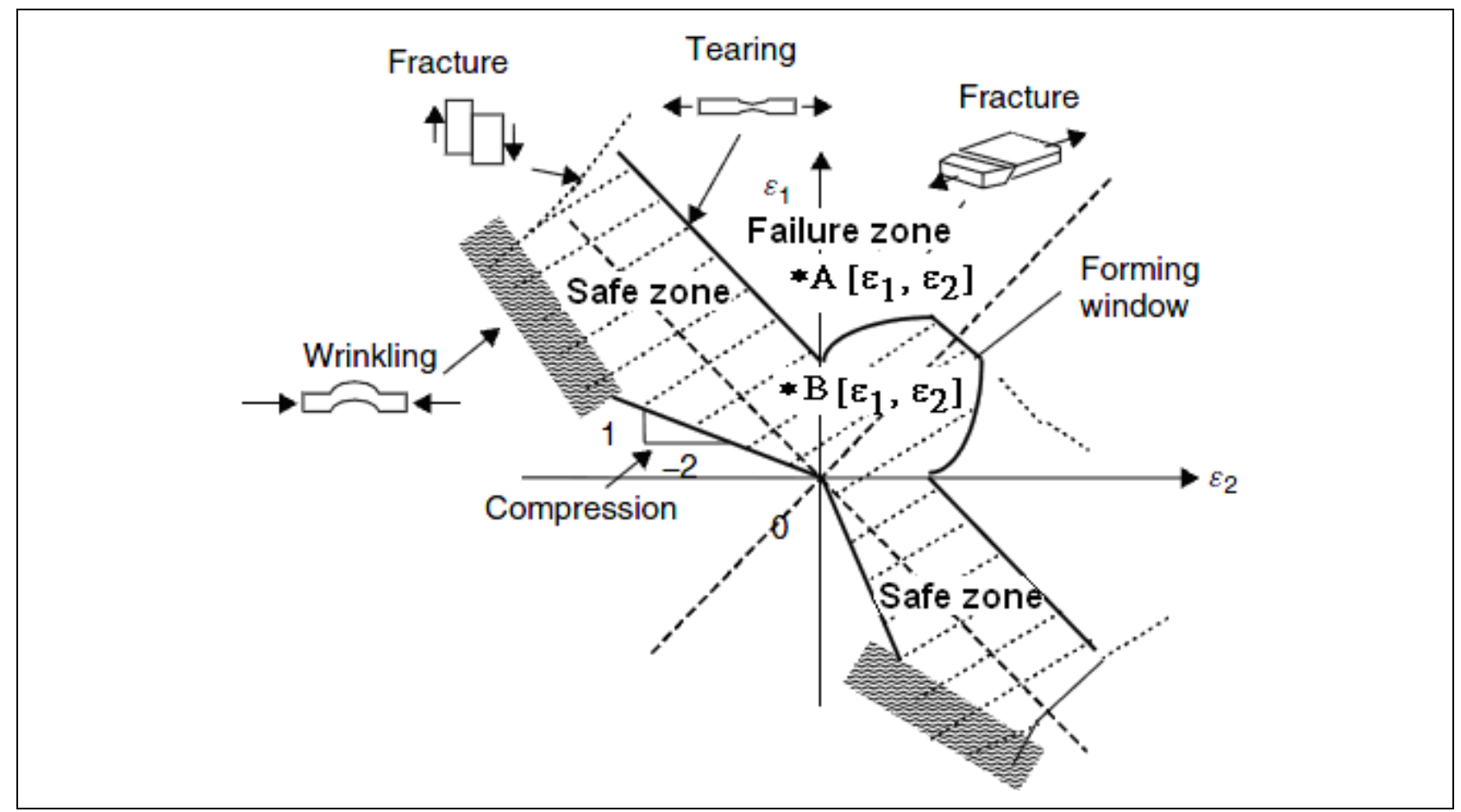

Fig. 1. Sheets formability window (Ramaekers, 2000) 
The stress state in sheet plane can be expressed by the main stresses ratio $\alpha=$ $\sigma_{2} / \sigma_{1}$ and a strain state by the main deformations ratio $\beta=\varepsilon_{2} / \varepsilon_{1}$ (Fig. 2), where the first main (major) deformation $\varepsilon_{1}>0$, the second main (minor) deformation $\varepsilon_{2}<0$ or $\varepsilon_{2}>0$.

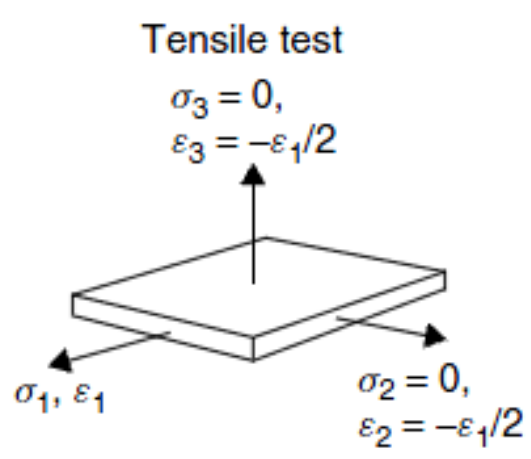

(a)

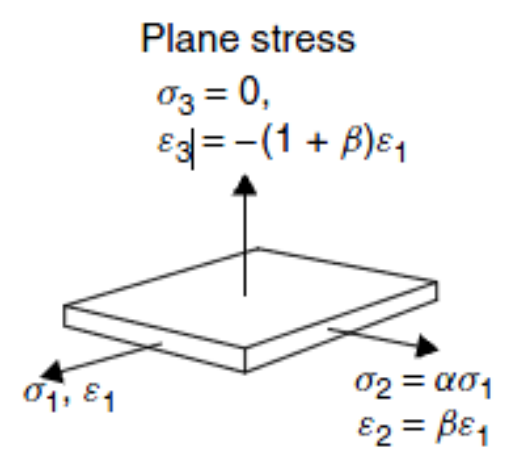

(b)

Fig. 2. Stress-strain states at stamping

At a certain combination of major and minor deformations $\varepsilon_{1}$ and $\varepsilon_{2}$ in sheet plane the localised deformation in critical area occurs, i.e. there comes to local area narrowing (the cup wall thickness) of the cross-section in critical area, followed by fracture. A combination level of the major and minor deformations in sheet plane before localised deformation (before a local narrowing) creates limit between good drawn parts - B point and failure drawn parts - A point. This dependence of limit deformations $\varepsilon_{1 \mathrm{c}}$ and $\varepsilon_{2 \mathrm{c}}$ in a sheet plane is known as Keeler-Goodwin forming limiting diagram - FLD. Nowadays, forming limiting curves (FLC) are considered as inseparable formability characteristic of steel sheets because they quote the development of deformation depending on time and also allows to identify a deformation mechanism depending on the strain state.

FLC curve position in FLD diagram depends not only on material properties, stress-strain state, but also on the initial blank thickness, strain rate and friction between blank-die contact surfaces. As it is shown in Fig. 1, maximal major deformation $\varepsilon_{1 \mathrm{c}}$ is located at the areas near to $\varepsilon_{1 \mathrm{c}}= \pm \varepsilon_{2}$. When $\varepsilon_{1 \mathrm{c}}=-\varepsilon_{2}$ wrinkling occurs at pressings production. At crash situations wrinkling occurs first, followed by fracture after overloading of the limit fracture deformation. The lowest values of major deformation $\varepsilon_{1 \mathrm{c}}$ are reached in areas at the minor deformation $\varepsilon_{2}=0$. In the area from $\varepsilon_{1 \mathrm{c}}=-2 . \varepsilon_{2}$ to $\varepsilon_{1 \mathrm{c}}=\varepsilon_{2}$ fracture occurs after local necking due to tensile stresses acting.

\section{Methods of experimental research}

Within last 50 years there was a lot of an experimental work done and a big effort invested in analytic and experimental creation of forming limit curves (Hrivňák, 2004), (Čada, 2001), (Mihalíková, 2010), (Ganesh Narayanan, 2008). In 
Wessely, E.; Evin, E. \& Tomas, M.: Prediction of Deformation Properties of Steel...

this contribution the results of limit deformations study are presented by both the CCD video camera recording method and based on a numerical simulation.

The austenitic stainless steel sheet DIN 1.4301 and deep drawing quality steel sheet DX54D were used as the experimental materials. Their chemical composition and mechanical properties are shown in Tab. 2 and Tab. 3.

\begin{tabular}{|l|c|c|c|c|c|c|c|}
\hline Material & $\mathrm{C}$ & $\mathrm{Mn}$ & $\mathrm{Si}$ & $\mathrm{P}$ & $\mathrm{S}$ & $\mathrm{Al}$ & $\mathrm{N}$ \\
\cline { 1 - 6 } DX 54 D & 0.05 & 0.2 & 0.02 & 0.009 & 0.01 & 0.049 & 0.006 \\
\cline { 1 - 5 } DIN 1.4301 & 0.07 & 2.0 & 1.0 & 0.045 & 0.03 & $\begin{array}{c}\mathrm{Cr} \\
19\end{array}$ & $\begin{array}{c}\mathrm{Ni} \\
10\end{array}$ \\
\hline
\end{tabular}

Tab. 2. Chemical composition of experimental materials [\%]

\begin{tabular}{|l|c|c|c|c|c|}
\hline Material & $\begin{array}{c}0.2 \% \text { YS } \\
{[\mathrm{MPa}]}\end{array}$ & $\begin{array}{c}\text { UTS } \\
{[\mathrm{MPa}]}\end{array}$ & $\begin{array}{c}\mathrm{K} \\
{[\mathrm{MPa}]}\end{array}$ & $\begin{array}{c}\mathrm{n}_{90} \\
{[-]}\end{array}$ & $\begin{array}{c}\mathrm{r}_{90} \\
{[-]}\end{array}$ \\
\hline DX 54 D & 184 & 311 & 487 & 0.215 & 1.59 \\
\hline DIN 1.4301 & 273 & 621 & 1491 & 0.515 & 0.99 \\
\hline
\end{tabular}

Tab. 3. Mechanical properties in $90^{\circ}$ to rolling direction

Localised plastic deformations were researched at deformation states within interval $\beta=(-1 / 2 ; 0)$. Deformation schemes were modelled on tensile test specimens with different notch radii: R5, R10, R17.5 and R25. Local limit deformations at experiments were researched using circle deformation grid $\left(l_{0}=2 \mathrm{~mm}\right)$ etched on test specimens.

Testing machine TIRAtest 2300 was utilized and a load velocity was set to 10 $\mathrm{mm} / \mathrm{min}$. The change of specimen's dimensions and grid's shape in a notch area was continuously recorded by CCD camera. Local limit deformations $\varepsilon_{1}=1_{1} / 1_{0}, \varepsilon_{2}=1_{2} / 1_{0}$ were calculated and evaluated by software Matlab's Image Processing Toolbox 1,5. An implemented video-recording method also allows researching all the deformations history from the test start to specimen fracture.

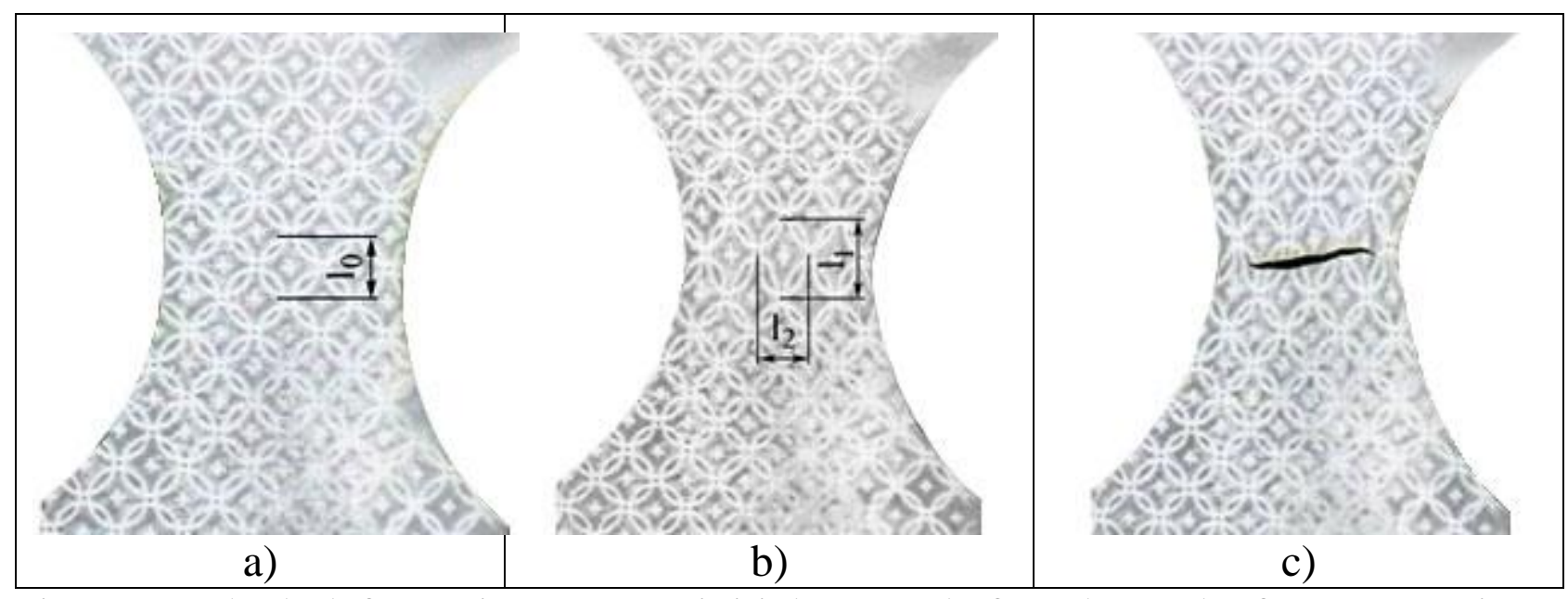

Fig. 3. Etched deformation net a) initial state, before b) and after c) specimen cracking 
Deformation net dimensions were evaluated before deformation (the initial state), before crack occurred (the limit state) and after crack occurred (specimen fracture) - see Fig. 3. Following assumptions were considered to define limit state of deformations based on a deformation history:

- homogeneous deformation occurs in the first phase, deformation history is linear $\varepsilon_{1 \mathrm{i}}$ $=\beta_{\mathrm{i} .}\left(-\varepsilon_{2 \mathrm{i}}\right) \cap \beta_{\mathrm{i}-1} \approx \beta_{\mathrm{i}}$,

- localised deformation (diffuse necking) occurs at the second phase under a constant loading, deformation history isn't linear $\varepsilon_{1 \mathrm{i}}=\beta_{\mathrm{i}} \cdot\left(-\varepsilon_{2 \mathrm{i}}\right) \cap \beta_{\mathrm{n}-2}>\beta_{1 \mathrm{n}-1}$,

- at the third phase localised neck (local necking) occurs of width $2 . \mathrm{a}_{0}$ and the sudden drop of loading force is recorded, followed by fracture, where $\varepsilon_{1 \mathrm{n}-1}<\varepsilon_{1 \mathrm{n}} \cap \varepsilon_{2 \mathrm{n}-1}=\varepsilon_{2 \mathrm{n}}$ $\cap \beta_{\mathrm{n}-1} \approx<\beta_{\mathrm{n}}$.

Deformations evaluated from net dimensions at the end of the second phase were defined as the limit deformations - Fig. 3a; deformations evaluated in the third phase aren't useful for application at stamping, because fracture occurs - Fig. $3 b$.

Numerical simulations of necked specimens were realised using Pam Stamp 2G simulation software. Specimens were modelled in 3D CAD/CAM software Pro/Engineer and exported into simulation software in neutral format igs. In Pam Stamp 2G specimens were meshed to the square finite elements with dimension $2 \mathrm{~mm}-$ Fig. $4 \mathrm{a}$.

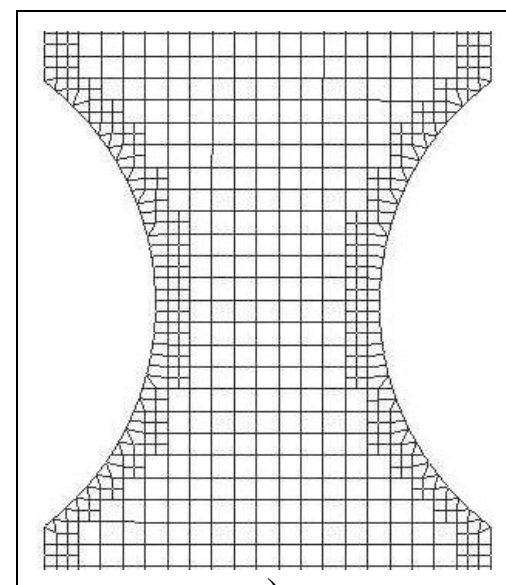

a)

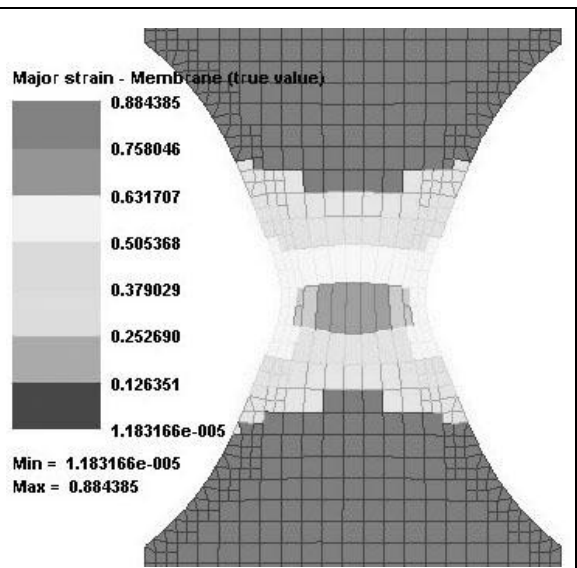

b)

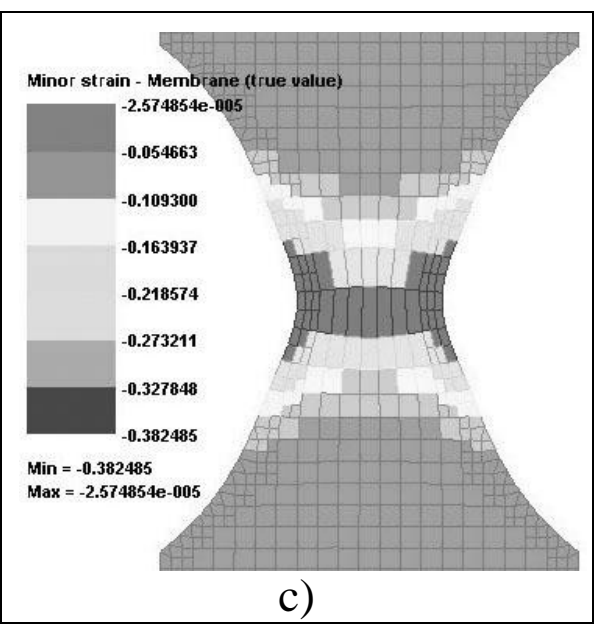

c)

Fig. 4. Meshed specimen - a) and limit state of major - b) and minor - c) strains in numerical simulation

To define mathematic models in Pam Stamp 2G following input data were set: basic material data (density, Young's modulus, Poisson's constant), blank thickness, strain-hardening curve defined by Hollomon's law according to data shown in Tab. 3, Lankford's coefficients, rolling direction $0^{\circ}$ in longitudinal axis of specimens, Yield law defined by Hill 48 model. (Park, 2010), (Hrivňák, 2004), (Kováč \& Tittel, 2010)

The localised deformations were shown in postprocessor by the visualisation of major $\varepsilon_{1}$ (Fig. $4 \mathrm{~b}$ ) and minor $\varepsilon_{2}$ (Fig. 4c) deformations.

\section{Reached results and discussion}

Fig. 5 and Fig. 6 show in graphs calculated limit deformations as well as deformation paths of the selected deformation net element with computed forming limit curves for both experimental materials. 
Wessely, E.; Evin, E. \& Tomas, M.: Prediction of Deformation Properties of Steel...

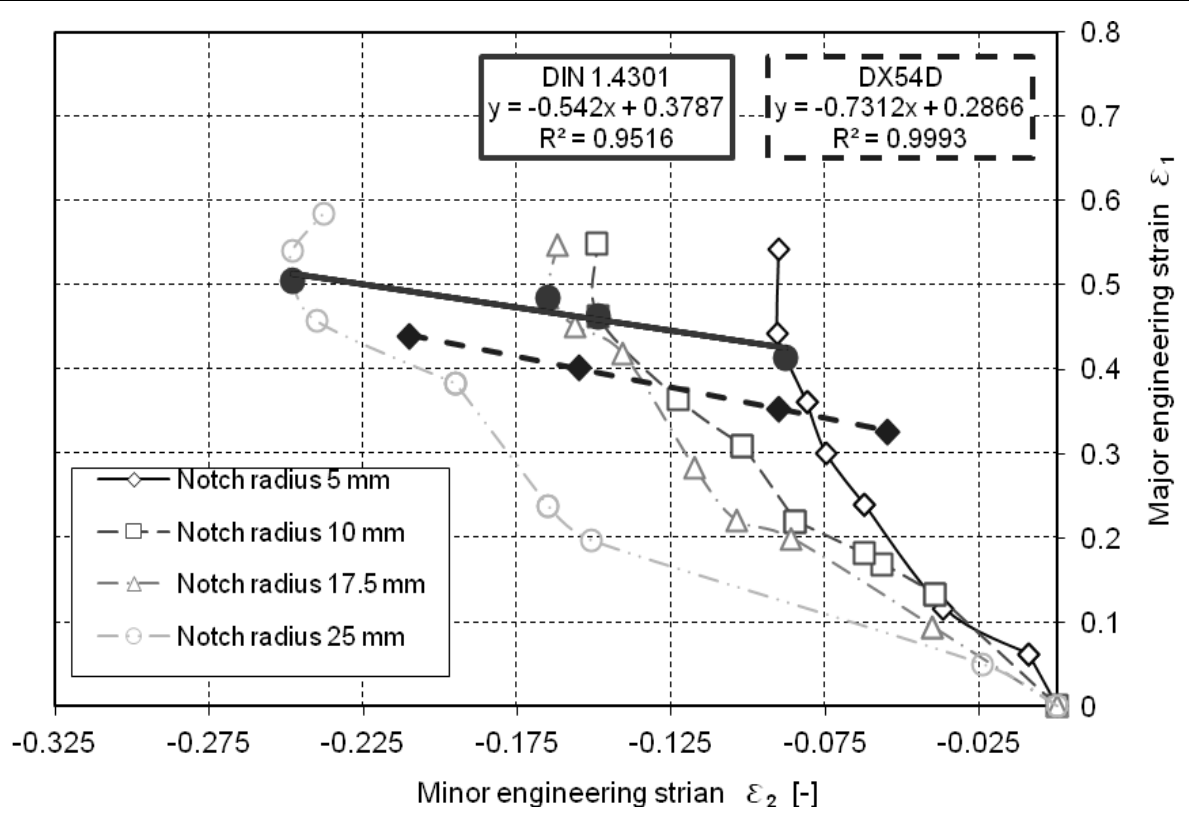

Fig. 5. Experimentally acquired forming limit curves

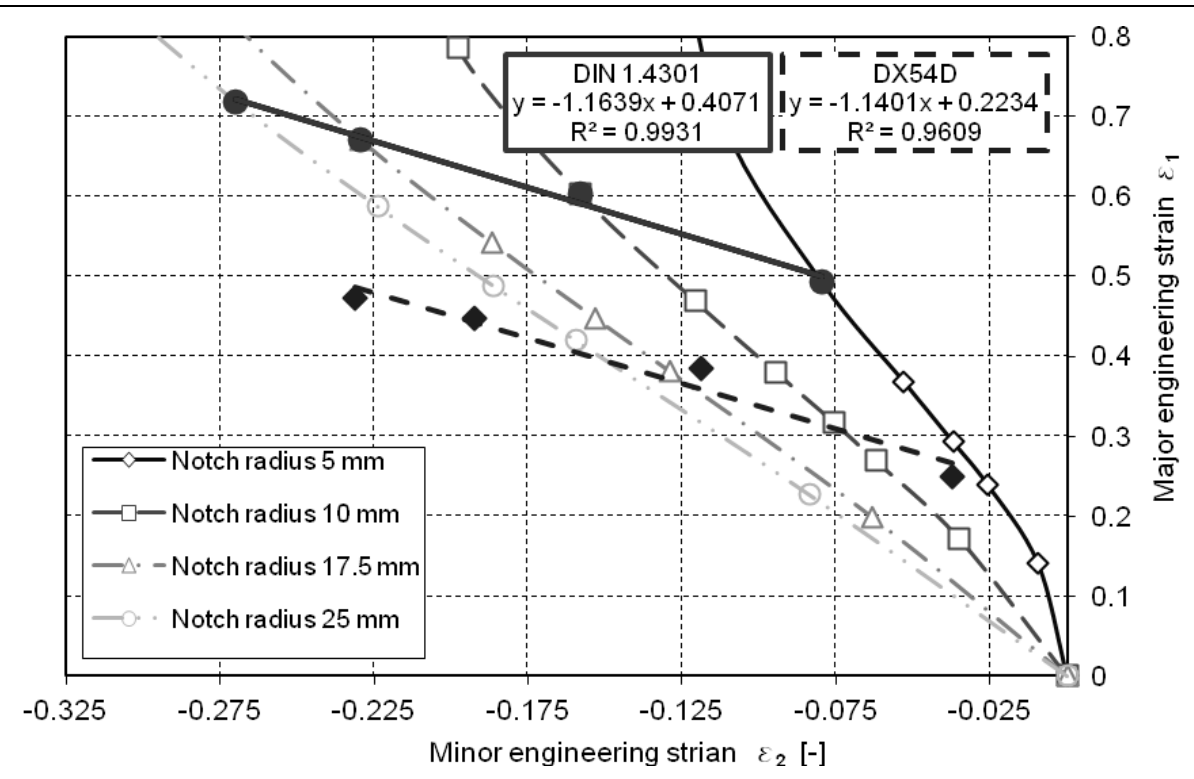

Fig. 6. Forming limit curves acquired from numerical simulation

The measured results of a plastic deformation distribution from tensile test of necked specimens show the deformation history is linear to the limit values described by FLC (Fig. 5). To define limit formability criteria more important are limit values of deformation in sheet's plane, resp. thinning before localisation of plastic deformation (neck creation). If we put a curve through the points where there is a significant change of line slope (the critical value of deformation), we get the left part of the FLC. Comparing the FLC defined for an austenitic steel sheet DIN 1.4301 (Fig. 5) and hot deep galvanized steel sheet DX54D the FLC is situated the higher, the higher values of elongation and strain hardening exponent are. The values of these material characteristics are in the austenitic steel sheet larger than the values in low carbon steel sheet DX54D (Tab. 3). The measured results show that the position 
of the FLC isn't affected by a normal anisotropy ratio (austenitic steel sheet $r=1$, low carbon steel sheet $\mathrm{r}=1.8$ ). Reached FLC comply with the present knowledge (Hrivnnák, 2004), (Chow, 2002), (Mishra, 2009). The finding that the position of FLC depends largely on the elongation and strain hardening exponent confirmed the results obtained with strain rate $\varphi^{\prime}=0.0083 \mathrm{~s}^{-1}$. When changing the strain rate from $0.0007 \mathrm{~s}^{-1}$ to $0.0083 \mathrm{~s}^{-1}$ there came to approximately $1 \%$ shift for the material DIN1.4301 as well as for the material DX54D. When changing the strain rate from $0.0007 \mathrm{~s}^{-1}$ to $0.0083 \mathrm{~s}^{-1}$, the decrease about $3 \%$ in the elongation for austenitic steel sheet as well as the slight decrease about $2 \%$ in the elongation for drawing quality low carbon steel sheets were also recorded. (Hrivňák, 2004)

A comparison of FLC reached by experimental measurement (Fig. 5) and by numerical simulation (Fig. 6) show good agreement. Further research should be focused on the analysis of material models in relation to the FLC.

\section{Conclusion}

Knowing both the distribution and intensity of limit plastic deformation defined by forming limiting curves allows better utilisation of material properties at car's body production as well as crash tests. Reached results of presented study could be summarized as follows:

1. The forming limit curves for hot deep galvanized steel sheet DX54D and austenitic stainless steel DIN 1.4301 were stated by experiments based on CCD video camera recording of notched specimens' tensile test. The deformation properties of austenitic stainless steel DIN 1.4301 as innovative material were compared to deformation properties of hot deep galvanized steel sheet DX54D.

2. The FLC for austenitic stainless steel DIN 1.4301 is situated higher than FLC for hot deep galvanized steel sheet DX54D. That means position of FLC depends greater on the plastic properties (strain hardening exponent, elongation) than on yield stress and normal anisotropy ratio. The lowest values of $\varepsilon_{1 \mathrm{c}}$ were reached for both experimental materials during the plane deformation state $\varepsilon_{2}=0$.

3. The higher values of $\varepsilon_{1 \mathrm{c}}$ are, the deformation work resp. ability to absorb kinetic energy at frontal impact increases. Comparing FLC for experimental materials, the car's body parts produced from austenitic stainless steel have greater ability to absorb kinetic energy than these ones produced from hot deep galvanized steel.

4. By application of austenitic stainless steel for car's body frontal impact deformation zones is car deceleration given by eq. $\mathrm{a}_{\max }=\mathrm{v}_{0} \frac{\mathrm{m}}{\mathrm{k}}=\frac{\mathrm{v}_{0}^{2}}{\Delta \mathrm{L}_{\max }}$ lower than by application of hot deep galvanized steel because of critical deformation and then critical value of shortening $\Delta \mathrm{L}_{\max }$ of parts produced from austenitic stainless steel is higher than produced from hot deep galvanized steel.

5. By application of austenitic stainless steel for car's body lateral impact deformation zones pre-deformation of parts is necessary (by hydromechanical forming etc.) to reach desired plastic deformation and to avoid passenger's space reduction. 
Wessely, E.; Evin, E. \& Tomas, M.: Prediction of Deformation Properties of Steel...

6. The difference between FLC experimentally measured by CCD video camera recording and computed from numerical simulation for both materials is higher than $\pm 2.5 \%$. The next research should be focused to improvement of FLC evaluation by numerical simulation.

\section{Acknowledgements}

This contribution was working out with the support of grant project VEGA $1 / 0824 / 12$ "Study of tribology aspects of formability of coated steel sheets and tailored blanks" and as a result of project implementation: Centre for research of control of technical, environmental and human risks for permanent development of production and products in mechanical engineering (ITMS: 26220120060) supported by the Research \& Development Operational Programme funded by the ERDF.

\section{References}

Čada, R. (2001). Formability of steel sheets. Repronis, Ostrava 2001, p.346, ISBN: 80-86122-77-8

Chow, C. L. \& Yang, X. J. \& Chu, E. (2002). Prediction of forming limit diagram based on damage coupled kinematic-isotropic hardening model under nonproportional loading. Journal of Engineering Material Technology. Vol. 124, No. 2, pp. 259-265 (2002), ISSN 0094-4289

Ganesh Narayanan, R. \& Narasimhan, K. (2008). Predicting the forming limit strains of tailor welded blanks. Journal of Strain Analysis for Engineering Design. Vol. 43(7), pp. 551-563, ISSN 0309-3247

Hrivňák, A. \& Evin, E. (2004). Formability of steel sheets. Elfa, Košice, p.223, ISBN80-89066-93-3

Kováč, P. \& Tittel, V. (2010). Blank holder force optimization of hemispherical product using numerical simulation. Materials science and technology, No.5, pp.5-10, ISSN: 1335-9053

Mihalíková, M. \& Ambriško, L. \& Pešek, L. (2010): The hardness analysis of the if steel sheet after a plastic deformation. Chemicke listy (S). Vol. 104, No. 15 (2010), s350-s352, ISSN 1213-7103

Mishra, S. K., et all (2009). Improved predictability of forming limit curves through microstructural inputs. International Journal of Material Forming, Vol. 2, No.1 (2009), pp 59-67, ISSN 1960-6206

Park, H. \& Anh, T. V. (2010). Different Methods In Analyzing Roll Forming Process Of Automotive Component, Chapter 07 in DAAAM International Scientific Book 2010, pp. 057-072, B. Katalinic (Ed.), Published by DAAAM International, ISBN 978-3-901509-74-2, ISSN 1726-9687, Vienna, Austria

Ramaekers, J.A.H. (2000). A Criterion for Local Necking. Journal of Materials Processing Technology, Vol. 103, No. 1 (2000), pp.165-171, ISSN 0924-0136

Rosenberg, G. et all (2011). Analysis of Fe-Al interphase layer in Zn-coating of steel HX180YD. Chemicke listy (S). Vol. 105, No. 16 (2011), s568-s570, ISSN 1213-7103 